\title{
DO VALOR/ALUNO/ANO AO CUSTO-ALUNO-QUALIDADE- INICIAL: O CONTROLE SOCIAL NA CONSOLIDAÇÃO DOS FUNDOS CONSTITUCIONAIS COMO POLÍTICA DE ESTADO
}

\author{
Wellington Ferreira de Jesus *
}

\begin{abstract}
RESUMO
O presente trabalho, um estudo exploratório, tem como referência uma pesquisa em fontes documentais como Documentos do Executivo e do Legislativo, Propostas de Emendas e Emendas Constitucionais, a Lei de Diretrizes e Bases, a legislação pertinente ao financiamento da educação básica, bem como a literatura que discute o tema. Este artigo objetivou refletir a perspectiva de participação social e efetivação de uma Política de Estado para o setor educacional, a partir da instituição dos Fundos Constitucionais para o financiamento da Educação Básica brasileira no transcurso histórico da segunda metade da década de 1990 e início do século XXI. A política de fundos fomentou o debate no campo do financiamento da educação, na medida em que possibilitou um debate amplo que discute: a problemática dos recursos; a participação social no controle e no acompanhamento; a ação do Ministério Público e de órgãos como a Controladoria Geral da União e os Tribunais de Conta; o fomento à pesquisa $\mathrm{e}$ participação das universidades, tanto no levantamento de estudos de impacto, quanto na perspectiva da capacitação e do aperfeiçoamento do magistério; além de consolidar a importância da gestão democrática e dos conselhos escolares.
\end{abstract}

Palavras-chave: Financiamento da Educação Básica. Custo Aluno Qualidade. Custo Aluno Qualidade Inicial

\section{ABSTRACT \\ FROM THE COST PUPIL/YEAR TO THE COST PUPIL/INICIAL QUALITY: SOCIAL CONTROL IN THE CONSOLIDATION OF THE CONSTITUTIONAL FUNDS AS STATE POLICIES}

This exploratory study used as references various documents such as Legislative text and official Executive Documents, Amendments Proposals and Constitutional Amendments, the Brazilian Federal Guidelines for Education, laws upon financing of Basic Education, as well as literature that discusses the subject, aiming to analyze the perspective of social participation and implementation of a State Policy for education starting from the creation of the Constitutional Funds for financing basic education in Brazil throughout the historical time-line of the second half of the 1990 s and beginning of the $21^{\text {st }}$ century. The funds policy provoked debate in the

\footnotetext{
* Doutor em Educação pela Universidade Federal de Goiás (UFG). Professor Adjunto do PPGE da Universidade Católica de Brasília (UCB). Endereço para correspondência: Universidade Católica de Brasília. Programa de Pós-Graduação em Educação, 716 Norte-AE. Brasília-DF. wellingtonfj@gmail.com
} 
field of education funding, as it led to a wider debate about the following: the issue of resources, social participation in control and monitoring; the action of Prosecutor and organs, such as the national ombudsman, Court of Accounts, the promotion of research and participation of universities, both in the survey of impact studies, and in view of training and improvement of teaching, besides consolidating the importance of democratic management and school board.

Keywords: Financing of Basic Education. Cost of Quality education per Student. Cost of inicial quality education per Student.

\section{Introdução}

No contexto dos desdobramentos históricos do financiamento, a educação, no Brasil, assume um caráter de significação e centralidade, a partir da segunda metade da década de 1990, com a instituição de fundos destinados à manutenção e ao desenvolvimento do ensino fundamental e, posteriormente, abarcando toda a educação básica. Esse processo foi permeado de contradições, avanços, limitações e, especialmente, de forma mais significativa, possibilitaram a participação da sociedade civil organizada, tanto nos debates quanto na elaboração e no desenvolvimento do processo.

A instituição da política de fundos para o financiamento da Educação Básica trouxe à tona um conjunto de estudos, pesquisas, debates, levantamentos de resultados e impacto, discussões sobre o regime de colaboração entre os entes federativos e a sua real efetivação, e expuseram as ações dos governos no sentido do não cumprimento da vinculação constitucional, da má utilização dos recursos públicos e da dimensão do significado do direito à educação, como uma garantia e uma conquista da cidadania, entre outros. Em outras palavras,

$[\ldots]$ os fundos, como o Fundef ou o Fundeb [...] forçam a discussão conjunta entre a União, os Estados e os Municípios sobre quais são os valores considerados suficientes, necessários e/ou possíveis de serem investidos em educação. Essas discussões, em si mesmas, são democratizadoras, pois temos melhores condições de saber como funcionam os mecanismos de captação, distribuição e gasto dos recursos educacionais (ARELARO; GIL, 2006, p. 76).

Sob esse prisma, a política de fundos complexificou o debate no campo do financiamento da educação, na medida em que possibilitou um debate amplo que discute: a problemática dos recursos; a participação social no controle e no acompanhamento; a ação do Ministério Público (MP) e de órgãos como a Controladoria Geral da União (CGU) e os Tribunais de Contas (TCs); o fomento da pesquisa e participação das universidades, tanto no levantamento de estudos de impacto, quanto na perspectiva da capacitação e do aperfeiçoamento do magistério; além de consolidar a importância da gestão democrática e dos conselhos escolares.

Este trabalho, um estudo exploratório, tendo por uma referência uma pesquisa em fontes documentais tais como os Documentos do Executivo e do Legislativo, Propostas de Emendas e Emendas Constitucionais, a LDB, a legislação pertinente ao Fundef (BRASIL, 1996a) e ao Fundeb (BRASIL, 2007, 2008a), bem como a literatura que discute o tema, objetivou refletir a perspectiva de participação social e efetivação de uma Política de Estado para o setor educacional, a partir da instituição dos Fundos Constitucionais para o financiamento da Educação Básica brasileira no transcurso histórico da segunda metade da década de 1990 e das primeiras décadas do século XXI. Nesse sentido, aqui se entende Política de Estado como as políticas "que envolvem mais de uma agencia do Estado, passando em geral pelo Parlamento ou por instâncias diversas de discussão, resultando em mudanças de outras normas ou disposições preexistentes, com incidência em setores mais amplos da sociedade" (OLIVEIRA, 2011, p. 329).

\section{O Fundef: a "expansão encolhida" e o valor/aluno/ano}

Ao refletir sobre o papel da política de fundos no contexto do financiamento à Educação Básica no Brasil, situando-a na perspectiva dos avanços 
por ela constituídos, é preciso compreender que qualquer pesquisa, estudo ou análise sobre a atual política de fundo para o financiamento da educação básica deve ter como referência imediata uma análise sobre a instituição do "Valor/aluno/ano" (CAQ) e do custo-aluno-qualidade-inicial (CAQI) como referências de construção de uma política de Estado de financiamento ao nível básico no Brasil.

Destaca-se, nesse sentido, a dimensão de uma “expansão encolhida", no caso do Fundef, criado em 1996, durante a gestão do presidente Fernando Henrique Cardoso (1995-2002). Em outras palavras, o fundo era integrante de uma política social focalizada.

Foi objeto da Lei $n^{\circ}$ 9.424/1996 (BRASIL, 1996a) o estabelecimento do valor mínimo anual por aluno, que deveria ser fixado por ato do presidente, exceto no ano de 1997. Conforme o art. $6^{\circ}$, no parágrafo $1^{\circ}$, o valor não poderia ser inferior à razão entre a previsão de receita do Fundef e o número de matrículas do ano anterior, acrescido das novas matrículas, conforme o censo educacional.

Para considerar a perspectiva e as contradições do valor/aluno/ano, deve-se buscar o seu significado e de que forma ele se coloca no contexto da subvinculação. A definição de valor/aluno/ano considera a existência de uma

1-Despesa anual por aluno, ou seja, medida de caráter não-financeiro dos recursos ou 'inputs' educacionais. 2. Custo por aluno, por ano, relacionado a um nível determinado de ensino. Consegue-se dividindo as despesas totais do nível específico de ensino de um determinado ano, pelo número de alunos do mesmo nível e ano. 3. Pode compreender o orçamento-aluno - disponibilidade orçamentária por aluno; o custo-benefício - investimentos em níveis e modalidades educacionais que conseguem maiores taxas de retorno econômico - e o custo-qualidade que envolve critérios objetivos e subjetivos de aferição de desempenho, além de avaliações que abranjam a dinâmica das necessidades do sistema. (INSTITUTO NACIONAL DE ESTUDOS E PESQUISAS EDUCACIONAIS ANÍSIO TEIXEIRA, 2005, p. 2).

No estabelecimento do valor-aluno-ano, o principal parâmetro utilizado constituiu-se das estimativas de recursos de impostos disponíveis, considerando a vinculação e os fundos constitu- cionalmente estabelecidos. Assim, a prioridade está condicionada aos recursos orçamentários, e não às necessidades do setor educacional.

Dessa forma, não existia uma efetiva participação da sociedade na construção dos referenciais, na discussão orçamentária e mesmo na definição do valor/aluno/ano. Cabia ao Governo Federal tomar as decisões e deliberações a partir de critérios estabelecidos pelo próprio Executivo, tendo sempre como referência a posição da "equipe econômica". Contudo, ainda no contexto do desenvolvimento e das contradições do Fundef, estudos e pesquisas propuseram uma alternativa: a instituição do conceito de custo-aluno ${ }^{1}$ e do custo-aluno-qualidade (CAQ). Tendo por referência tanto a legislação educacional brasileira quanto o disposto na Constituição Federal de 1988, a criação do CAQ tem como ponto de partida o

[...] levantamento dos indicadores da qualidade do ensino e do conseqüente dimensionamento dos seus custos, com intuito de avaliar, a partir daí, a necessidade de recursos financeiros para a educação, seja em termos de montante global, seja de prioridades e proporcionalidade na sua alocação [...]. Não há dúvida que estas disposições [Constitucionais, LDB] encaminham para uma concepção de custo por aluno mais abrangente do que um valor mínimo por aluno, calculado a partir da razão entre a previsão de receitas e a matrícula. (LUCE; FARENZENA, 1999, p. 71-72).

Dessa maneira, o conceito de CAQ desenvolveu-se a partir de um amplo debate sobre os padrões de financiamento, a qualidade do ensino e parte da ideia central sobre qual o recurso gasto por aluno para se ter um ensino de qualidade (MONLEVADE, 1997; MONLEVADE; FERREIRA, 1998; LUCE; FARENZENA, 1999; VERHINE, 2005; VERHINE; MAGALHÃES, 2006; ARELARO; GIL, 2006; BACIC, 2004; SOUZA JUNIOR, 2001; PINTO, 1999, 2000, 2002; GOMES, 1997; DAVIES, 2001; FARENZENA, 2003). A elaboração do CAQ envolveu uma ampla participação que, em coerência com a legislação vigente, buscou definir os insumos que deveriam compor uma escola com padrões básicos de qualidade (PINTO; CARREIRA, 2007).

$1 \mathrm{O}$ conceito de custo-aluno pode ser considerado como fruto direto da Campanha Nacional em Defesa da Educação. 
A Lei $n^{\circ} .9 .424$ (BRASIL, 1996a) sinalizou como critério para o estabelecimento do custo/aluno as matrículas no ensino fundamental. Segundo Pinto (2000, p. 106), esse critério significava o "ponto chave do Fundef", pois a União poderia fixar percentuais mínimos que resultassem no avanço da complementação da capacidade dos recursos dos Estados.

No entanto, as avaliações sobre o valor anual aluno/ano, complementação do Fundef (MONLEVADE; FERREIRA, 1998; DAVIES, 2001, 2008; RAMOS, 2003; MELCHIOR, 1997; MACHADO, 2000; PINTO, 2002), convergiram para o fato de que as verbas não eram suficientes para suprir o valor estabelecido.

\section{O Fundeb: da "esperança ao medo"?}

No desenvolvimento da campanha eleitoral que levou o candidato Luís Inácio Lula da Silva à Presidência da República, especialmente durante o segundo turno, ganhou destaque a frase "a esperança venceu o medo" ${ }^{2}$. Esta foi pronunciada por Lula em meio a um clima de tensão, acusações e propagandas que demonstravam a possibilidade de uma crise e catástrofe geral no país, no caso de uma eventual vitória do referido candidato. A dialética da "esperança frente ao medo" absorveu a temática de uma campanha em que as críticas ao modelo vigente eram feitas de maneira genérica e encaminhavam para uma continuidade. De certa forma, essa "dialética" se apresentou, embora no sentido inverso, ou seja, "da esperança ao medo", para o financiamento a educação brasileira, sobretudo no caso da Educação Básica, com o Fundeb.

Estruturalmente, o Fundeb manteve diversos aspectos característicos de seu antecessor, o Fundef, caracterizando-se como um fundo contábil de âmbito estadual, com a abrangência em todos os Estados brasileiros, incluindo o Distrito Federal. No âmbito de cada Estado, o Fundeb reúne os governos em nível estadual e municipal. Conforme Callegari (2009, p. 63-64), "Instituído em modelagem única,

2 Destaca-se um momento dessa tensão, quando uma atriz muito conhecida nos meios da televisão brasileira na década de 1970 como "a namoradinha do Brasil", que encabeçava a propaganda eleitoral, afirmou sentir muito medo de uma possível vitória do candidato Lula com relação a uma violenta desordem que se abateria sobre o país. o FUNDEB é singular, Estado a Estado e no Distrito Federal: os vinte e sete FUNDEBs implantados não se correlacionam, nem interagem entre si”. Dessa forma, por não se constituir como um fundo da União, e nem mesmo um fundo estadual, tem sua interligação em nível nacional e estadual limitada às regras de funcionamento, bem como à sua finalidade.

No desenvolvimento do percurso legislativo, que resultou na criação do Fundeb, destaca-se como uma das mais significativas referências a PEC $\mathrm{n}^{\circ}$ 112 (BRASIL, 1999), que propunha, a partir dos avanços experimentados pelo Fundef, uma nova redistribuição de recursos, o caráter de vinculação receita/ matrícula, a perspectiva da descentralização, a possibilidade de um controle social de recursos mais eficiente, entre outros aspetos. Tais considerações apresentavam-se consensualmente superiores ao estado anterior, no qual predominava uma autonomia ou regulação dos entes federativos com relação aos recursos destinados ao setor educacional, resultando em uma situação de abusos e descontrole, e utilização ilegal das verbas públicas.

$\mathrm{O} \S 2^{\circ}$, do art. $4^{\circ}$, bem como o art. $7^{\circ}$ da Lei ${ }^{\circ}$ 11.494 (BRASIL, 2007) estabelecem uma relação intrínseca entre o valor aluno/ano e a garantia de "padrões de qualidade" na educação básica. A definição de qualidade da educação, objeto de estudos e pesquisas recentes, é que se trata de "um fenômeno complexo, abrangente, e que envolve múltiplas dimensões, não podendo ser apreendido apenas por um reconhecimento da variedade e das quantidades mínimas de 'insumos' considerados indispensáveis ao desenvolvimento do processo de ensino aprendizagem" (DOURADO; OLIVEIRA; SANTOS, 2007, p. 9, grifo do autor); contudo, não se pode negligenciá-los.

Segundo Pinto e Carreira (2007), como um conceito construído histórica e socialmente, a qualidade na educação pública brasileira ou a sua ausência foram objetos de preocupação de estudos desde o século XIX. De certa forma, pode-se afirmar que, em síntese, predominou entre a construção da instrução pública no Brasil, no período monárquico, até o final da década de 1970, durante a ditadura militar, a concepção de educação elitista ou da "qualidade para poucos" (PINTO; CARREIRA, 2007, p. 20). A partir dos anos de 1980, a visão de qualidade na 
educação deslocou-se para a ideia de gestão eficiente, ou seja, associar os indicadores de rendimento e eficiência, garantindo o acesso e a permanência. A partir do final dos anos de 1980 e, sobretudo, na década de 1990, integrante do processo de discussão do compromisso "educação para todos", bem como das reformas educacionais, a concepção de qualidade na educação passou a incorporar

[...] a relação entre os recursos materiais e humanos, bem como a partir da relação que ocorre na escola e na sala de aula, ou seja, os processos de ensinoaprendizagem, os currículos, as expectativas de aprendizagem com relação à aprendizagem das crianças, etc. (DOURADO, OLIVEIRA, SANTOS, 2007, p. 9).

No Brasil, o cerne da discussão sobre a qualidade na educação teve por marco jurídico-institucional a Constituição de 1988. O art. 206, inciso VI, determina a "garantia do padrão de qualidade" para a educação; o art. $211, \S 1^{\circ}$ dispõe a garantia de "equalização de oportunidades educacionais e padrão mínimo de qualidade do ensino", tendo como referência a assistência técnica e financeira da União aos governos subnacionais; o art. 214, inciso III, ao determinar a existência do Plano Decenal de Educação, afirma que se objetiva a "melhoria da qualidade do ensino" (BRASIL, 1988). A Lei n 9.394 (BRASIL, 1996b), no art. 3o, propõe a "garantia de padrão de qualidade" como princípio do ensino e a define no art. $4^{\circ}$, inciso IX: "variedade e quantidade mínimas por aluno, de insumos indispensáveis ao desenvolvimento do processo de ensino-aprendizagem". No seu art. 70, inciso IV, faz referência à qualidade. Além disso, nos arts. 71 e 72 destaca-se o regime de colaboração, sobressaindo o estabelecimento de "padrão mínimo de oportunidades educacionais para o ensino fundamental, baseado no cálculo do custo mínimo por aluno, capaz de assegurar ensino de qualidade". Já nos artigos 74 e 75 , estabelece que a suplementação da União far-se-á de forma a suprir a capacidade de atendimento de cada ente federado, referente à oferta do ensino dentro de um padrão mínimo de qualidade definido nacionalmente ${ }^{3}$. (BRASIL, 1996b).

\footnotetext{
3 Cabe o registro de que, passada quase uma década e meia da aprovação da LDB, essa garantia de "padrões de qualidade" ainda requer regulamentação.
}

\section{Do CAQ ao CAQI: a participação da so- ciedade}

Analisando a legislação educacional brasileira de 1988 até o ano de 2006, é possível identificar a existência de um "[...] quadro normativo que, embora ainda permeado de ambiguidades, fornece elementos para que se saia do padrão de recurso disponível" (PINTO, 2006, p. 87). E, ainda, que se estabeleça um CAQ que se situe muito além do privilégio técnico ou dos sacrifícios dos orçamentos, portanto além dos valores aluno/mês estipulados pelo Fundef e do Fundeb.

Entretanto é preciso considerar que, no contexto das reformas e dos ajustes estruturais que caracterizaram a década de 1990, o sentido de qualidade na educação acompanhou a proposta da "eficiência", ou seja, a consecução de muitas metas com poucos recursos (PINTO; CARREIRA, 2007). Dentro da lógica da competição do mercado, os testes e avaliações padronizadas assumem centralidade, objetivando estimular a competição entre escolas e os resultados como o produto obtido pelo "cliente", mesmo que não se considerassem a diversidade e a heterogeneidade do país, da região, das redes públicas e, em particular, dos próprios alunos.

Essa visão de qualidade da educação aliada ao estabelecimento de testes padronizados de avaliação e constante das propostas de organismos multilaterais,

os documentos da Comissão Econômica para América Latina e Caribe (Cepal), ao abordarem a questão da qualidade da educação, enfatizam a necessidade do desenvolvimento de ferramentas e diagnósticos por meio de provas ou outros instrumentos de aferição da qualidade. Segundo a Cepal, a avaliação é fundamental para o monitoramento das políticas e para orientar as intervenções no campo educativo. (DOURADO; OLIVEIRA; SANTOS, 2007, p. 12).

De maneira geral, constituiu-se uma espécie de transposição das leis de mercado ao campo da educação que caracterizou as reformas da década de 1990, que foram, inicialmente, negligenciadas por setores de representação das organizações e lideranças populares que

[...] rejeitaram a pauta da qualidade, afirmando se tratar de um debate neoliberal. Porém, num segundo 
momento, esse tema começou a aparecer na agenda da garantia dos direitos. No final da década de 1990, o debate qualidade versus equidade ganha força com o nome de 'qualidade social'. Preconiza-se que não há qualidade baseada em critérios democráticos que represente exclusão (10\% vão ficar dentro e $90 \%$ vão ficar fora?). (PINTO; CARREIRA, 2007, p. 21).

Dessa forma, é preciso entender que o conceito, quando se reflete sobre qualidade social, só se define a partir de uma inter-relação e articulação entre diversos sujeitos e processos envolvidos com a perspectiva de uma democratização da sociedade.

Contribuiu para constituir os padrões mínimos necessários a uma escola de qualidade, compreender que

[...] muito além da sala de aula, espera-se que as escolas contemporâneas garantam aos alunos acesso a determinadas facilidades que contribuam para sua formação. A existência de bibliotecas, salas de informática com acesso à internet, quadras de esporte, entre outros fatores, além de estimular a frequência dos alunos, contribui para uma formação mais completa e eficaz. (CAMPOS; CRUZ, 2009, p. 384).

Estabelecer os padrões mínimos de qualidade de ensino, considerando as quantidades mínimas por aluno-ano, e de insumos imprescindíveis ao processo de ensino-aprendizagem conduzem para concretizar as condições de realização do trabalho pedagógico e nas condições das escolas, da gestão escolar, da realidade socioeconômica dos alunos e profissionais de educação. É revelador que estudos sobre a

[...] qualidade da Educação revelam, também, que uma educação de qualidade, ou melhor, uma escola eficaz é resultado de uma construção de sujeitos engajados pedagógica, técnica e politicamente no processo educativo, em que pesem, muitas vezes, as condições objetivas de ensino, as desigualdades socioeconômicas e culturais dos alunos, a desvalorização profissional e a possibilidade limitada de atualização permanente dos profissionais da educação. Isso significa dizer que não só os fatores e os insumos indispensáveis sejam determinantes, mas que os trabalhadores em educação (juntamente com os alunos e pais), quando participantes ativos, são de fundamental importância para a produção de uma escola de qualidade ou que apresente resultados positivos em termos de aprendizagem. (DOURADO; OLIVEIRA; SANTOS, 2007, p. 11).
Ao refletir sobre a qualidade na educação, entende-se que ela se fundamenta no conceito de "qualidade social", pois possibilita: o respeito ao Estado de Direito; a democratização das relações político-sociais; entender que as desigualdades regionais, sociais e educacionais estão inseridas no próprio contexto de contradições históricas do Brasil; permitir a participação na gestão; e interligar quantidade e garantia de sucesso. No entanto é no campo do financiamento à educação que a concepção de qualidade democrática tem sua amplitude revelada, ao exigir " [...] investimentos financeiros de longo prazo [...]" (PINTO; CARREIRA, 2007, p. 24) e reconhecer as necessidades e diversidades que caracterizam o país. Esses são os padrões necessários para se pensar em um CAQ na perspectiva da qualidade social.

Nesse sentido, o CAQ pode ser definido como o custo potencial de um aluno da educação básica durante o período de um ano, recebendo um ensino de qualidade. O CAQ deve objetivar que a "educação básica pública adquira e se realize com base em um padrão mínimo de qualidade", funcionando como "uma alternativa ao atual desequilíbrio regional e à oferta de educação básica pública" (CONFERÊNCIA NACIONAL DE EDUCAÇÃO, 2010, p. 104, grifo do autor).

Os indicadores de qualidade e dos custos em educação estão interligados e vinculam-se diretamente "[...] aos projetos de educação e de sociedade a que se aspira [...]" (LUCE; FARENZENA, 1999, p. 74). Não se pode subestimar o respeito ao regime de colaboração entre os entes federativos no estabelecimento do CAQ, na medida em que estão diretamente ligados à capacidade de atendimento, à arrecadação tributária dos estados e municípios e à ação supletiva e redistributiva da União.

Considerando a perspectiva dos fundos constitucionais, pode-se observar que a EC no 14/1996 "[...] ensaiou a introdução de uma concepção de custo-qualidade, ao prever o ajuste progressivo, no prazo de cinco anos (2001) das contribuições dos entes federados ao fundo, de modo a garantir um valor, por aluno" (MARTINS 2006, p. 62).

Trata-se do CAQ, correspondente a um padrão mínimo de qualidade do ensino, definido nacionalmente. No entanto, o dispositivo que instituiu o CAQ foi ignorado pela gestão FHC. Castro 
(2006), ao analisar as contradições e limitações da passagem do Fundef ao Fundeb, apresentou a perspectiva dos orçamentos, a preocupação com a manutenção do ajuste fiscal e do superávit primário como entraves que impediram de priorizar ou até mesmo estabelecer o CAQ. Nesse sentido, pode-se considerar que, com relação ao Fundef,

[...] diminuiu a diferença custo/aluno, principalmente no âmbito estadual, mas não convergiu para um custo/aluno/qualidade, previsto na lei, até porque o Ministério da Educação também não nos diz quanto é o custo/aluno/qualidade hoje: não sabemos. [...] A questão do custo/aluno/qualidade é: ao se fixar valor muito alto, se tem um problema orçamentário, pois a Fazenda [Ministério da Fazenda] acaba não nos financiando. Em geral, o grande debate sempre desemboca na Fazenda, ou seja, significa aplicar mais ou menos recursos para a educação. O custo/ aluno é isso. (CASTRO, 2006, p. 22).

Monlevade e Friedmann (2006) consideraram que cabe à União estabelecer esses CAQ, e que sejam

[...] diferenciados por etapa e modalidade de ensino, uma vez que os insumos em cada processo são diferentes e de custos igualmente distintos. É óbvio, por exemplo, que o CAQ de uma creche onde a criança fica 10 horas por dia e a professora cuida de grupos menores, será maior que de uma escola fundamental onde um professor trabalha numa classe de 30 alunos, somente 4 horas diárias. $\mathrm{O}$ valor de cada CAQ, em tese, deve derivar de um estudo dos componentes ou insumos que garantem a qualidade do ensino-aprendizagem, à luz dos preços médios vigentes no mercado. Entretanto, ele não pode estar desatrelado da potencialidade de financiamento de cada Estado. Daí a expressão padrão mínimo de qualidade. (MOLEVADE; FRIEDMANN, p. 121-122).

Entretanto, no Fundeb, não foram definidos os critérios de cálculo referentes à complementação da União em relação às séries iniciais do ensino fundamental. Não está claro se os valores fixados não se baseiam na proposta do CAQ de cada nível e modalidade da educação básica, que constava na PEC n ${ }^{\circ} 112 / 1999$ (DAVIES, 2008). O disposto na Lei $n^{\circ} 11.494$ (BRASIL, 2007) utiliza um critério contábil, segundo o $\S 1^{\circ}$ do art. $4^{\circ}$, na complementação da União, embora o art. 10, ao estabelecer pesos diferenciados para as matrículas, utilize um critério pedagógico. Davies (2008) afirma que, tanto o $\$ 2^{\circ}$ do art. 10 , quanto o art. 13 retomam a lógica financeira em prejuízo da ideia de qualidade, com o referencial centrado na dimensão pedagógica. Davies (2008, p. 46) argumenta que a indefinição dos critérios que estabelecem o CAQ, no Fundeb, resulta do "maior peso da chamada 'equipe econômica' (os gerentes do superávit primário)".

A problemática da definição do CAQ, a partir de critérios pedagógicos, é significativamente reforçada quando se observa a disparidade regional e intrarregional do Brasil. Campos e Cruz observaram, em pesquisa sobre o impacto do Fundeb, na rede municipal do Rio de Janeiro, que essa disparidade se apresenta também entre o ensino médio e fundamental, pois

[...] o primeiro apresenta uma oferta de infraestrutura complementar muito mais notável. Ainda que apresente um número bem menor de alunos, o que pode facilitar a oferta de infraestrutura, o desempenho do ensino médio tem superado o desempenho do ensino fundamental em todas as análises já apresentadas. Resta saber se, dada a expansão no número de alunos prevista para a modalidade com a implementação do Fundeb, a oferta de infraestrutura complementar para a maior parte dos alunos de ensino médio público permanecerá sendo assistida (2009, p. 15).

Considerando a polissemia e a natureza histórico-social de conceitos como qualidade, educação e, como tal, qualidade na educação, em geral antagônicas e sob a perspectiva de quem controla o poder, compreende-se essa indefinição ou "ausência de critérios claros" no que tange ao CAQ (PINTO; CARREIRA, 2007; DAVIES, 2008), o que contribuiu para desenvolver a ideia de um custo-aluno-qualidade-inicial, CAQI (PINTO; CARREIRA, 2007).

Considerando o fato de que os padrões ou critérios que determinam o conceito de qualidade são dinâmicos e modificam-se historicamente no processo de construção do CAQ, nasceu a ideia de estabelecer um ponto de partida, um padrão mínimo assegurado a todas as escolas do Brasil. É, portanto, dos debates que originaram o CAQ que surge o conceito de CAQI (PINTO; CARREIRA, 2007).

Criado em 2006 como fruto de debates, conferências, estudos, pesquisas e oficinas da Campanha 
Nacional Pelo Direito à Educação ${ }^{4}$, o CAQI está alicerçado em três colunas principais: implantar o piso para os professores; melhorar a infraestrutura das escolas; e garantir um mínimo de alunos por sala de aula. Conforme Pinto e Carreira (2007, p. 79), quatro são os fatores que impactam diretamente o CAQI: "tamanho da escola/creche; jornada dos alunos e das alunas (crianças no caso da educação infantil); relação alunos/crianças-turma ou alunos/ crianças-professor; e o salário das e dos profissionais da educação."

$\mathrm{Na}$ perspectiva da qualidade almejada pela Campanha Nacional pelo Direito à Educação, o CAQI é um indicador dinâmico e cresce à medida que melhora a qualidade da educação exigida pela população. São utilizados como referência os insumos indispensáveis ao desenvolvimento dos processos de ensino e aprendizagem e há uma diferenciação conforme níveis, etapas e modalidades. O CAQI amplia a ideia de valorização para todos os profissionais da educação, bem como considera os parâmetros de infraestrutura e qualificação docente.

Conforme estimativas de Pinto e Carreira (2007), o impacto financeiro do CAQI na rede pública em 2005 demandaria um aporte inicial de aproximadamente $1 \%$ do PIB, “[...] índice sem dúvida elevado, mas absolutamente de acordo com as disponibilidades do País" (2007, p. 112).

\section{Considerações Finais}

Considera-se que a proposta de estabelecimento do valor/aluno/ano, predominante no Fundef e com reflexos na constituição do Fundeb, ajusta-se mais a uma visão de controle do Governo e, de forma particular, da "área econômica" sobre as demandas e decisões da sociedade no que tange às políticas públicas e sociais, especialmente a educação.

O CAQ representou uma passagem para a consolidação de outra realidade, mas ainda man-

4 Criada em 1999, a Campanha Nacional Pelo Direito à Educação se define como "[...] rede social que articula mais de 200 entidades de todo o Brasil, incluindo sindicatos, movimentos sociais, organizações não governamentais, universidades, grupos estudantis, juvenis e comunitários e muitas outras pessoas que acreditam que um país cidadão somente se faz com uma educação pública de qualidade. É a articulação mais plural e ampla no campo da Educação Básica." (CAMPANHA NACIONAL PELO DIREITO À EDUCAÇÃO, 2009). tendo vínculos com efetividade de uma política de governo em detrimento de uma política de Estado para a educação brasileira. A construção do CAQI representa uma possibilidade de ruptura, não apenas no sentido das prioridades e da alocação de recursos, mas, entre outros aspectos, pelo caráter de efetiva participação social.

Pode-se considerar que o CAQI nacional funcionaria somente como um parâmetro mínimo, a fim de que nenhuma administração municipal invista um menor percentual de recursos na educação quando comparada aos investimentos da União (PINTO; CARREIRA, 2007).

O Documento Final da CONAE 2010 (CONFERÊNCIA NACIONAL DE EDUCAÇÃO, 2010), ao considerar a relevância do CAQ, propôs as bases estruturais para definir o CAQI, ao reafirmar a necessidade de um amplo debate em torno de questões como: a remuneração adequada e a formação continuada dos profissionais de educação; os insumos necessários à aprendizagem dos alunos; a observância das desigualdades regionais e locais, resultando na prioridade às escolas "com menos acessos a esses recursos" (CONFERÊNCIA NACIONAL DE EDUCAÇÃO, 2010, p. 106). Nesse sentido, cabe ressaltar o significado da Resolução n 8/2010 (BRASIL, 2010), do Conselho Nacional de Educação (CNE), aprovada em 05 de maio, que representou um avanço significativo e, ao mesmo, sintetiza o resultado significativo desse processo histórico, ainda em construção, dos fundos constitucionais de financiamento da educação básica, inseridos na dinâmica do financiamento a esta educação no Brasil ${ }^{5}$. Todavia, considerados os limites e possibilidades da dinâmica histórica do financiamento à educação, particularmente a Educação Básica, cabe registrar que, até o final do primeiro semestre de 2011, não foi homologada pelo MEC a Resolução $n^{\circ}$ de 8/2010 (BRASIL, 2010), do CNE.

\footnotetext{
5 Em 05 de maio de 2010, o CNE aprovou a Resolução no 8/2010, que normatiza os padrões mínimos de qualidade da educação básica. Conforme a resolução aprovada, foram determinados os percentuais do PIB per capita, anualmente corrigidos em cada etapa da educação básica (BRASIL, 2010).
} 


\section{REFERÊNCIAS}

ARELARO, L. R.; GIL, J. C. Política de fundos na educação: duas posições. In: LIMA, M. J. R.; DIDONET, V. FUNDEB - avanços na universalização da educação básica. Brasília: MEC/INEP, 2006. p. 71-88.

BACIC, J. M. O custo-aluno no ensino fundamental público: reflexões para a gestão municipal a partir dos resultados de uma pesquisa de campo. Florianópolis: Intercostos, 2004. Disponível em: $<$ http://www.intercostos. org/documentos/122.pdf > . Acesso em: 20 jan. 2011.

BRASIL. Presidência da República. Lei 11.494, de 20 de junho de 2007. Regulamenta o Fundo de Manutenção e Desenvolvimento da Educação Básica e de Valorização dos Profissionais da Educação - FUNDEB, de que trata o art. 60 do Ato das Disposições Constitucionais Transitórias; altera a Lei oㅜ 10.195, de 14 de fevereiro de 2001; revoga dispositivos das Leis nos 9.424, de 24 de dezembro de 1996, 10.880, de 09 de junho de 2004, e 10.845, de 05 de março de 2004; e dá outras providências. Disponível em: <http://www.planalto.gov.br/ccivil_03/_ato20072010/2007/Lei/L11494.htm>. Acesso em: 10 ago. 2007.

Presidência da República. Lei 9.424, de 24 de dezembro de 1996. Dispõe sobre o Fundo de Manutenção e Desenvolvimento do Ensino Fundamental e de Valorização do Magistério, na forma prevista no art. $60, \S 7^{\circ}$, do Ato das Disposições Constitucionais Transitórias, e dá outras providências. Brasília, 1996a. Disponível em: <http:// www.planalto.gov.br/ccivil_03/leis/L9424.htm>. Acesso em: 10 ago. 2007.

Câmara dos Deputados. Proposta à Emenda Constitucional n. 112, de 20 de outubro de 1999. Modifica os arts. 208, 211 e 212 da Constituição Federal e o art. 60 do Ato das Disposições Constitucionais Transitórias, criando o Fundo de Manutenção e Desenvolvimento da Educação Básica Pública e de Valorização dos Profissionais da Educação. Disponível em: <http://www.camara.gov.br>. Acesso em: 04 jun. 2007.

Ministério da Educação. CONFERÊNCIA NACIONAL DE EDUCAÇÃO BÁSICA - Documento Final. Brasília: MEC, 2008a. Disponível em: <http://portal.mec.gov.br/arquivos/conferencia/documentos/doc_final.pdf>. Acesso em: 10 out. 2008.

Presidência da República. Constituição da República Federativa do Brasil de 1988. Brasília, 1988. Dis-

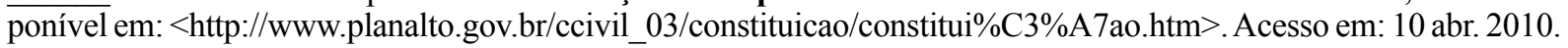

Presidência da República. Lei 9.394, de 24 de dezembro de 1996. Lei de Diretrizes e Bases da Educação Nacional. Estabelece as diretrizes e bases da educação nacional. Brasília, 1996b. Disponível em: $<$ http://www. planalto.gov.br/ccivil_03/leis/L9394.htm>. Acesso em: 10 mar. 2009.

Presidência da República. Lei 11.738, de 16 de julho de 2008. Regulamenta a alínea "e" do inciso III do caput do art. 60 do Ato das Disposições Constitucionais Transitórias, para instituir o piso salarial profissional nacional para os profissionais do magistério público da educação básica. Brasília, 2008b. Disponível em: <http:// www.planalto.gov.br/ccivil_03/_ato2007-2010/2008/lei/111738.htm>. Acesso em: 12 abr. 2011.

. Ministério da Educação. Conselho Nacional de Educação. Resolução n⿳0 8, de 05 de maio de 2010. Estabelece normas para aplicação do inciso IX do artigo $4^{\circ}$ da Lei $n^{\circ}$ 9.394/96 (LDB), que trata dos padrões mínimos de qualidade de ensino para a Educação Básica pública. Disponível em: <http://portal.mec.gov.br/index.php?option=com_cont ent\&view=article\&id=12992\&Itemid=866> . Acesso em: 10 out 2010.

CAllegari, C. (Org.). O Fundeb e a educação pública no Estado de São Paulo. São Paulo: Aquariana-Apeoesp, 2009.

CAMPOS, B. C.; CRUZ, B. de P. A. Impactos do Fundeb sobre a qualidade do ensino básico público: uma análise para os municípios do estado do Rio de Janeiro. Revista de Administração Pública - RAP, Rio de Janeiro, FGV, n. 42, p. 371-393, mar./abr. 2009.

CAMPANHA NACIONAL PELO DIREITO À EDUCAÇÃO. São Paulo, 2009. Disponível em: <http://www. campanhaeducacao.org.br>. Acesso em: 20 abr. 2010.

CASTRO. J. A. de. O Fundeb e as necessidades de financiamento da educação básica (âmbitos nacional e estadual). In: SANTOS, Ricardo Ferreira dos. O FUNDEB e os desafios da educação básica. Brasília: Câmara dos Deputados, 2006. p. 19-52.

CONFERÊNCIA NACIONAL DE EDUCAÇÃO. CONAE - 2010. Construindo o Sistema Nacional Articulado de Educação: o Plano Nacional De Educação, Diretrizes e Estratégias de Ação. Documento Final. Brasília: MEC, 2010. 
Disponível em: <http://www.portal.mec.gov.br/arquivos/pdf/conae/texto_conae.pdf>. Acesso em: 20 mar. 2010.

DAVIES, N. FUNDEB: a redenção da educação básica? Campinas: Autores Associados, 2008.

O FUNDEF e as verbas da educação. São Paulo: Xamã, 2001.

DOURADO, L. F.; OLIVEIRA, J. F. de; SANTOS, C. de A. A qualidade da educação: conceitos e definições. Brasília: MEC/INEP, 2007. Disponível em: <http://escoladegestores.mec.gov.br/site/8-biblioteca/pdf/qualidade_da_educacao.pdf $>$. Acesso em: 10 abr. 2008.

FARENZENA, N. Análise da PEC 112/99. Boletim Controle Social, Porto Alegre, p. 1-2, 2003. Disponível em: $<$ http://www.controlesocial.org.br/boletim/ebul05>. Acesso em: 10 maio 2010.

GOMES, C. A. Alocação de recursos para a educação em tempo de crise. Revista Iberoamericana de Educación, Madrid, n. 14, p. 69-84, 1997.

INSTITUTO NACIONAL DE ESTUDOS E PESQUISAS EDUCACIONAIS ANÍSIO TEIXEIRA. Custo-Aluno. Brasília, 2005. Disponível em: $<$ http://www.inep.gov.br/pesquisa/thesaurus/thesaurus.asp?te1=31674\&te2=14717 7\&te $3=121399 \&$ te $4=121404>$. Acesso em: 20 abr. 2008.

LUCE, M. B.; FARENZENA, N. Custos educacionais - notas metodológicas de uma revisão da legislação e da literatura brasileiras. In: DOURADO, L. F. Financiamento da educação básica. Campinas: Autores Associados; Goiânia: Editora da UFG, 1999. p. 61-84.

MACHADO, M. A. de M. O Plano Decenal e os compromissos de Jomtien. In: INEP. Educação para todos: a avaliação da década. Brasília: MEC/INEP, 2000. p. 39-52.

MARTINS, P. de S. Financiamento da educação básica: critérios, conceitos e diretrizes. In: LIMA, M. J. R.; DIDONET, V. FUNDEB - avanços na universalização da educação básica. Brasília: MEC/INEP, 2006. p. 49-70.

MELCHIOR, J. C. de A. O financiamento da educação e a nova LDB. Educação Municipal, São Paulo, n. 3, dez. 1997.

MONLEVADE, J. A. C. de. Educação pública no Brasil: contos \& de\$conto\$. Ceilandia, DF: Ideia, 1997.

; FERREIRA, E. B. O FUNDEF e seus pecados capitais: análise do Fundo, suas implicações positivas e negativas e estratégias de superação de seus limites. Brasília: Ideia, 1998.

; FRIEDMANN, R. Sobre a viabilidade financeira do Fundeb. In: LIMA, M. J. R.; DIDONET, V. FUNDEB - avanços na universalização da educação básica. Brasília: MEC/INEP, 2006. p. 117-144.

OLIVEIRA, D. A. Das políticas de governo à política de Estado: reflexões sobre a atual agenda educacional brasileira. Educação e Sociedade, Campinas, v. 32, n. 115, p. 323-337, abr./jun. 2011.

PINTO, J. M. R. Um fundinho chamado "Fundão". In: DOURADO, L. F. (Org.). Financiamento da educação básica. Campinas: Autores Associados; Goiânia: Editora da UFG, 1999. p. 85-98.

Os recursos para a educação no Brasil no contexto das finanças públicas. Brasília: Plano/INEP, 2000. . Financiamento da educação no Brasil: um balanço do governo FHC (1995-2002). Educação e Sociedade, Campinas, v. 23, n. 80, p. 108-135, set. 2002.

O custo-aluno-qualidade na legislação. In: GOUVEIA, A. B.; SOUZA, A. R. de; TAVARES, T. M (Org.). Conversas sobre o financiamento da educação. Curitiba: Editora da UFPR, 2006. p. 73-88.

; CARREIRA, D. Custo aluno-qualidade inicial: rumo à educação pública de qualidade no Brasil. São Paulo: Global, 2007.

RAMOS, A. M. P. O financiamento da educação brasileira no contexto das mudanças político-econômicas pós-90. Brasília: Plano, 2003.

SOUSA JUNIOR, L. de. O FUNDEF e o direito à educação básica. REUNIÃO ANUAL DA ASSOCIAÇÃO NACIONAL DE PÓS-GRADUAÇÃO E PESQUISA EM EDUCAÇÃO, 24., 2001, Caxambu, MG. Anais eletrônicos... Caxambu, MG: ANPEd, 2001. Disponível em: <www.anped.org.br>. Acesso em: 24 maio 2008.

VERHINE, R. E. Levantamento do custo-aluno-ano em escolas de Educação Básica que oferecem condições de oferta para um ensino de qualidade - $2^{\text {a }}$ Etapa. Salvador: MEC/INEP, 2005. 
; MAGALHÃES, A. L. Custo-aluno em escolas de qualidade: uma análise por contexto e oferta de ensino. In: GOUVEIA, A. B.; SOUZA, A. R. de; TAVARES, T. M. (Org.). Conversas sobre o financiamento da educação. Curitiba: Editora da UFPR, 2006. p. 89-116.

Recebido em 14.09.12

Aprovado em 02.10 .12 